\title{
ATOMISMO E METAFÍSICA NOTAS SOBRE O CARTESIANISMO NA NÁPOLES DE VICO
}

\author{
Sertório de Amorim e Silva Neto
}

\begin{abstract}
RESUMO
O objetivo deste artigo é expor um breve quadro da presença de Descartes na filosofia napolitana de Sei-Settecento. Inicialmente, nas duas primeiras partes do texto, analisamos a fortuna do filósofo francês no interior da Accademia degli Investiganti, sobremaneira em D'Andrea, e a associação da sua imagem ao atomismo, que o colocaria como peça chave das censuras dirigidas aos inovadores napolitanos pela Igreja. Na terceira e última parte do texto, buscamos mostrar a mudança de fisionomia sofrida por Descartes após a fundação da Accademia di Palazzo del Duca di Medinaceli. Nosso interesse foi contrastar as leituras do pensador francês fazendo emergir, das obras de autores como Caloprese, Doria e Vico, as linhas gerais de um cartesianismo metafísico em condição não só de esvaziar o conteúdo das críticas jesuíticas, mas também de instituir as novas funções da classe dos intelectuais na vida do Vice-Reino.
\end{abstract}

Palavras-chave: Cartesianismo. Atomismo. Metafísica. Nápoles.

\begin{abstract}
The purpose of this article is to present a brief picture of Descartes presence in Neapolitan philosophy of Sei-Settecento. Initially, in the first two parts of the text, we analyze the fortune of the French philosopher inside the Accademia degli Investiganti, greatly in D'Andrea, and the association of image to atomism, which would place him as a key part of the reproaches addressed to the Neapolitans innovators for the Church. In the third and final part of the text we show the changes of physiognomy suffered by Descartes after the founding of the Accademia di Palazzo del Duca di Medinaceli. Our interest was to contrast the readings of the French thinker giving rise, of the works of authors such as Caloprese, Doria and Vico, the outlines of Cartesian metaphysical in a position not only to empty the contents of

* Doutor em Filosofia pela Faculdade de Filosofia, Letras e Ciências Humanas, da Universidade de São Paulo (USP) Professor do Instituto de Filosofia da Universidade Federal de Uberlândia (IFILO-UFU) e bolsista do Programa de Pós-Doutorado no Exterior da CAPES.E-mail: sertorio@defil.ufu.br
\end{abstract}


the jesuit criticism, but also to introduce the new functions of the class intellectual in the Viceroyalty life.

Keywords: Cartesian. Atomism. Metaphysics. Naples.

L’immortale Renato de le Carte Che Rinato immortal sia dalle Carte (CAMPAILLA, L'Adamo, Canto V).

Descartes foi um autor de grande fortuna na Nápoles de Sei-Settecento. A despeito dos rígidos interditos da contra-reforma e da sua declarada antipatia pelos italianos, sublinhada por Garin ${ }^{1}$, o pensador francês se consolidaria como "patrimônio filosófico meridional". Ao lado de Galileu, Bacon e Gassendi, Descartes vinha assimilado no sul da península sob o signo da libertas philosophandi e no interior da desconfiança diante do sectarismo e do acolhimento doutrinário das ideias, isto é, como "o principal autor", escreveu Francesco D'Andrea, da chamada "filosofia livre", que "não está ligada aos princípios das escolas", ou "eletiva, porque elege de todas as seitas aquilo que cada uma tem de bom"3, não sendo por isso interpretado ali como sistema: aos pedaços, destacados de tal modo do contexto do seu pensamento que consolidariam posições dessemelhantes e não raramente conflituosas nos círculos da Nápoles vichiana.

\section{I}

As ideias de Descartes chegariam àquela cidade, segundo testemunharam D’Andrea e Pietro Giannone, pelas mãos de Tommaso Cornelio, que após deixar a escola do renomado médico Marco Antonio Severino, em 1644, para alargar as experiências em Roma, Florença e Bolonha, voltou a Nápoles, cinco anos depois, trazendo na bagagem obras dos modernos: de

1 Baseando-se principalmente nas correspondências de Descartes, concluiu Garin: “A Descartes a Itália propriamente não agradava e, de fato, nem o agradavam os italianos, chamassem eles Cardano e Della Porta ou Galileu, fossem magos e charlatões ou grandes cientístas [...] os italianos pareciam a ele vaidosos, conversadores, vangloriosos. [...] $\mathrm{Da}$ Itália, pois, não suporta nem o clima, nem a cozinha, nem as epidemias, nem os delinquentes" (GARIN, 1990, p. 12 - 13).

2 LOMONACO, 2011, p. 12.

3 D'ANDREA, 1995, p. 148. 
Galileu, Gassendi, Bacone, Harvey, Boyle e, é claro, de Descartes ${ }^{4}$. Cornelio se tornaria professor de matemática na Universidade de Nápoles e junto de outros dois expoentes da cultura napolitana da época, D'Andrea e Leonardo di Capua, fundou a Accademia degli Investiganti com a qual se misturou e foi definida as representações iniciais do cartesianismo napolitano.

Para esta geração, Descartes foi, sobretudo, o físico investigador da natureza da luz, do movimento da matéria e do funcionamento dos organismos vivos num mundo corpuscular de regras que se demonstram geometricamente, ou melhor, o autor do Dioptrice, do Meteora, do Principia philosophiae e notabilizado propagandista do atomismo, fazendo coro com outros cientístas da época ${ }^{5}$. Destas leituras, os investiganti assimilaram o método e uma coesa cosmologia em grau de unificar os diferentes fenômenos naturais sobre pouquíssimos princípios simples e evidentes, "que não podem ser negados senão por quem esteja privado de sensatez" "eliminando o inconveniente da física até ali de ter que formular, avolumando o número de princípios (o vazio, os espaços não homogêneos, etc.), uma explicação $a d$ hoc para cada fenômeno. O problema, notava Cornelio, era que agindo deste modo a natureza deixaria de se comportar uniformemente e fúteis seriam as tentativas de adquirir dela o conhecimento científico, ainda que em termos probabilísticos. Pelo contrário, o valor da ciência estaria na formulação de hipóteses aptas a explicar não um fenômeno singular, mas o complexo dos fenômenos naturais e nisto, concordavam os investiganti, Descartes era insuperável ${ }^{7}$. Sua “doutrina dos átomos", escreveu D’Andrea:

ensina que todas as coisas sujeitas à geração e à corrupção compõemse de partículas diminutas e invisíveis, em nada diferentes entre si senão pelos seus movimentos, grandezas e figuras, e exclusivamente

${ }^{4}$ Cfr. RICCI, 1997, p. 251. Segundo detalhamento de Giuseppe Scerbo, que definiu as andanças de Cornelio como as de "um grego antigo por desejo de saber", em Roma Cornelio conheceu Michelangelo Ricci que o introduziu no estudo da matemática e da fisiologia, em Florença travou contato com Evangelista Torricelli que o introduzira nos estudos da física e da astronomia, e em Bolonha gozaria da instrutiva convivência com o matemático Bonaventura Cavalieri (SCERBO, 1933, p. 22 - 23).

5 Como aqueles citados por D'Andrea em sua Lezione: Boyle, Galileu, Gassendi, Redi e Regius.

6 D'ANDREA, 1995, p. 148.

7 TORRINI, 1977, p. 79. 
da composição, transposição e dissolução dessas partes e diversidade de seus movimentos e configurações nasce tudo isto que na natureza diziam gerar e se corromper ${ }^{8}$.

Ela, ao mesmo tempo, combate as formas de encantamento mágico da explicação física: prova ser desnecessário, não mais que capricho do arbítrio subjetivo, acrescentar à Física mais princípios, "como a forma, a privação, as formas substânciais, as acidentais, as parciais e cem outros vocábulos que se aprendem nas escolas", bastando, para os que filosofam sem extravagâncias na esteira da objetividade, "a variedade dos movimentos e das figuras" para conhecer com segurança "as causas de todos os efeitos naturais"

Em busca da objetividade e simplicidade da ciência natural, a estrada aberta pelo atomismo avançava na direção da censura ao aspecto abstrato, arbitrário e confuso da física praticada nas Escolas e sob o signo do aristotelismo. A proposição do atomismo redundava pois num litígio ideológico que ocuparia a atenção dos investiganti tanto quanto se ocupavam do estudo dos fenômenos naturais: era preciso eliminar da Físca os traços incômodos, metafísicos e teológicos, que dentro de um projeto de hegêmonia doutrinária se arrogavam a explicar o mundo das criaturas submetidas à geração e à corrupção corpóreas. No universo corpuscular outra coisa não existe senão matéria e movimento, e não é preciso supor outras coisas para explicá-lo, de modo que os conceitos de forma, substância e acidente podiam ser aposentadas pelos físicos do Seicento, guardadas nas gavetas das escrivaninhas ou jogadas no lixo dos conceitos. Praticar o atomismo na Nápoles do último Seicento, como fizeram os investiganti, implicava opor-se a toda pretensão da metafísica tradicional de inadvertidamente imiscuir seus temas e objetos com aqueles da Física. Uma decisão repleta de riscos, escreveu Borelli: "A instância rigorosamente anti-metafísica do atomismo de D'Andrea e dos seus amigos arriscava romper o equilíbrio sobre o qual estava fundado o consenso cultural e religioso da Igreja, vale dizer o nexo indissolúvel entre física e metafísica" 10 .

Convém abrir um parêntesis sem o qual não é possível compreender

\footnotetext{
8 D'ANDREA, 1995, p. 148.

9 D'ANDREA, 1995, p. 151.

${ }^{10}$ BORELLI, 1995, p. 37.
} 
com justeza a posição dos inovadores napolitanos. Não se tratava para eles de esvaziar os dogmas oficiais e as verdades da teologia, em vez disto, eram movidos pela ambição de garantir a separação e isenção dos domínios. Perseguindo o consenso dos teólogos, D'Andrea notava que a doutrina dos atomos, abraçada no início do Seicento por todos os bons espíritos, era coisa nova, ignorada portanto por mais de mil e seicentos anos, pelos antigos e pela religião cristã ${ }^{11}$, aportando novidades inclusive para a cristandade. $\mathrm{O}$ D'Andrea atomista não negou Deus como criador do mundo corpuscular, causa do movimento da matéria e responsável pela sua conservação, bem como excluiu do universo corpóreo "a alma racional, que não é gerada, mas criada e não se corrompe porque é imortal" 12 , admitindo assim premissas ligadas à fé. Para ele, problemático era admitir que sendo alguns fenômenos naturais incertos e obscuros, por isso deveriam ser apreendidos pelas notícias da teologia, posição esta contrária não só à física, mas principalmente à fé e à religião: "falsa, absurda, erética, plena de ignorância e destruidora não menos da própria fé que da ciência da natureza"

Um argumento próximo encontramos no oratoriano Nicolas Malebranche, confirmando a abertura de alguns religiosos às novidades da ciência dos modernos. Na Segunda Parte (Capítulo III) do Segundo Livro da De la recherche de la veritè Malebranche lista os motivos que levariam os homens a preferirem a opinião de outrem à luz natural na pesquisa da verdade, e inclui dentre elas o fato de que nas coisas da fé, que são fundadas na tradição e antiguidade dos argomentos, novidade e verdade não encontram acordo. Neste domínio, invés, o qualificativo novidade é confundido com erro e a verdade com o que dizem ser antigo: "Calvino, Lutero e outros inovaram e caíram no erro" 14 . Mas este raciocínio não pode se aplicar à nova ciência. $\mathrm{O}$ equívoco, alerta o oratoriano, é que as "almas vulgares" - presentes inclusive em muitos doutos religiosos - não distinguem frequentemente, o que os bons espíritos só fazem com grande fadiga, as verdades dependentes somente da razão daquelas dependentes da tradição, como as da fé, implicando que Galileu, Harvey e Descartes sejam mal compreendidos naquilo que dizem de novo. Sem que se faça tal distinção corre-se o risco de trair a luz natural

\footnotetext{
${ }^{11}$ D'ANDREA, 1995, p. 154.

${ }^{12}$ D'ANDREA, 1995, p. 151.

${ }^{13}$ D'ANDREA, 1995, p. $154-155$.

${ }^{14}$ MALEBRANCHE, 1819, Tomo III, p. 37.
} 
num silogismo de conclusões falsas do tipo: "A impanação de Lutero é nova e é falsa, logo, a circulação de Harvey é falsa porque é nova"15.

Fé e ciência se constroem segundo D'Andrea distintamente e a partir de princípios que não se implicam e por vias que não se cruzam. É preciso admitir que as certezas da fé são de espécie diferente das certezas científicas, e isto em favor da fé. Falando como protetor dos interesses da religião, escreveu D'Andrea: “quem dissesse que das coisas da fé podemos ter evidência diria um heresia condenada em cem Concilios". Se seus objetos possuíssem a evidência da natureza, a religião seria solapada em seus fundamentos, substraíndo dela os mistérios: tão simples quanto o corpo extenso e o movimento, seríamos obrigados a acreditar neles ainda que não quiséssemos e, por isso, não haveria nenhum mérito em neles crer nem nenhuma diferença entre cristãos e heréticos. Dizer que às coisas da fé possuem maior ou igual evidência que as naturais "nos tolhe o mérito na fé" por um lado e, por outro, porque são mistérios noticiados seja pelos anjos ou apóstolos, tolheria "a esperança de conseguir a cognição da verdade da natureza" ${ }^{16} \mathrm{e}$ a ciência.

Um aspecto destas teses de D'Andrea relevantes para a reconstrução da fortuna do cartesianismo em Nápoles, é a descontinuidade que estabelecem com a intenção de Descartes nas Meditações metafísicas, expressa no subtítulo da obra: a demonstração da existência de Deus, artigo de fé, por vias racionais. No Prefácio, dirigido aos teólogos de Paris, Descartes afirmaria o acordo da fé com a razão natural e a esta destinaria a função de único artifício capaz de convecer os infieis à conversão, ofercendo uma alternativa ao círculo sofístico em que se baseia a autoridade das Santas Escrituras ${ }^{17}$. Fica claro então o alheamento dos investiganti da metafísica cartesiana. Para eles, não se tratava tanto de oposição àquela metafísica quanto de um silêncio em relação à ela. Como observa Lojacono, "Não teria sido necessário haver diante dos olhos as Meditações para descobrir o iter metafísico da especulação cartesiana que, ainda que de forma menos fecunda e sugestiva, emergia também com clareza da IV parte do De Methodo e da primeria dos Principia, que foram, por sua vez, absolutamente ignoradas" 18 . O real interesse dos investiganti por Descartes se depreendia da Revolução

\footnotetext{
${ }^{15}$ MALEBRANCHE, 1819, Tomo III, p. 37.

${ }^{16}$ D'ANDREA, 1995, p. 155.

${ }^{17}$ DESCARTES, 1988, p. 85.

${ }^{18}$ LOJACONO, 1997, p. 73.
} 
Científica e da sua força em afirmar o valor do experiência transformada pela matemática renovada; neste contexto a filosofia se identifcava com física e com a medicina, era filosofia natural, e de modo algum metafísica ${ }^{19}$.

II

Os cuidados tomados por D'Andrea para garantir a isenção dos domínios da fé e da ciência natural não seriam contudo suficientes para a criação de um amplo consenso e para evitar reações anticartesianas da Igreja, como as do jesuíta e peripatético Giovanni Battista De Benedictis que, em 1694, sob o codinome de Benedetto Aletino, publicou em Nápoles as Lettere apologetiche in difesa della Teologia e della Filosofia peripatetica, livro que se tornaria famoso pelas reações polêmicas produzidas ${ }^{20}$. As Lettere consistiam em comentários do pensamento de Descartes que detalhavam suas incompatibilidades frente à concepção de mundo testemunhada por séculos pelos Padres e pela Igreja. Lojacono esclarece que a imagem de Descartes formada por De Benedictis não surgiria como produto da reflexão autônoma e pessoal do crítico jesuíta, mas como parte de uma estratégia de fôlego internacional, arquitetada pelos confraternos jesuítas, e destinada a subtraír credibilidade teórica e doutrinal aos cultores do novo saber ${ }^{21}$. Uma evidência disto era a presença no pano de fundo dos debates em torno das Lettere de De Benedictis do processo aos ateistas napolitanos instaurado pelo Santo Ofício em 1688. Agitador da vida cultural napolitana por quase uma década, alimentando ricas disputas intelectuais, como aquela do Aletino e seus adversários, o longo processo, cheio de encontros e desencontros, terminaria em 1697 sem maiores consequências para os réus ${ }^{22}$.

De Benedictis sustentaria em sua terceira Lettera que a concepção ato-

${ }^{19}$ LOJACONO, 1997, p. $71-73$.

${ }^{20}$ Dentre elas as as três respostas de Costantino Grimaldi (a primeira de 1699 e as outras duas de 1702 e 1703). Sobre o debate entre Aletino e Grimaldi páginas relevantes foram escritas por Ettore Lojacono (Immagine di René Descartes nella cultura napoletana (1644-1755). Lecce: Conte, 2003) e Giulia Belgioioso (La variata immagine di Descartes. Gli itinerari della metafisica tra Parigi e Napoli (1690-1733). Lecce: Milella, 1999).

${ }^{21}$ LOJACONO, 2003, p. 86.

${ }^{22}$ Para uma reconstrução detalhada e crítica do processo ver os frequentemente citados AMABILE, L. Il Santo Officio della inquisizione in Napoli. Catanazaro: Rubbetino, 1987 e OSBAT, L. L'Inquisizione a Napoli. Il processo agli ateisti. 1688-1697. Roma: Edizioni di Storia e Letteratura, 1971. 
mística da matéria de Descartes, como pura coisa extensa, possuía o grave inconveniente de eliminar do mundo criado todo fim providencialístico e, por isso, embora não se declasse ateísta, muito pelo contrário, servia a um próprio desestímulo à vontade de conhecer Deus, abrindo "uma estrada real ao acaso de Epicuro e ao ateísmo"23.

Estabelecer o império da extensão deixava sem respostas questões antes respondidas satisfatoriamente pela religião, como era o caso do milagre da Eucaristia. Descartes, escreveu De Benedictis, "Estabeleceu a natureza do corpo na extensão exclusivamente e assim tornou não somente falsa, mas impossível a contenção do Corpo Sagradíssimo do Senhor sob as espécies sacramentais" ${ }^{24}$. Como explicar que na Eucaristia o pão e o vinho, ainda que conservando as qualidades sensíveis do sabor, odor e aspecto, deixavam de ser pão e vinho para se tornarem o corpo e o sangue de Cristo? Para o raciocínio da nova ciência era impossível, pois enquanto simples agregado de átomos, o pão e o vinho permaneceriam idênticos em suas propriedades após a consagração. Outra interrogação deixada sem resposta, profundamente polêmica, dizia respeito à intervenção dos anjos no mundo material. Se todos os efeitos produzidos no mundo mecânico são sempre e somente causados pelo contato dos corpos, inclusive o fenômeno da luz, como entender as intervenções angelicais? De seres que não sendo corpos ainda assim movem os corpos e produzem efeitos naturais? Por causa destas coisas, diria o jesuíta De Benedictis, o católico Descartes foi sempre apreciado entre luteranos ${ }^{25}$.

Vale lembrar o alerta de Malebranche supracitado sobre a impanação de Lutero: algo novo no plano da fé e por isso falso; é sugestivo não só porque lança luzes sobre um dos temas da polêmica jesuítica com os cartesianos de Nápoles, mas porque ajuda a perceber melhor a mistura que aos investiganti cabia purificar: apartar Descartes e a nova filosofia das polêmicas teólogicas e debates doutrinários da contra-reforma.

Estas circunstâncias culturais da Nápoles do final do Seicento receberiam uma atenção especial em notáveis páginas da autobiografia de Giambattista Vico, sendo incluídas entre os eventos decisivos de sua formação intelectual, que permitem se "conheçam as próprias e naturais causas

\footnotetext{
${ }^{23}$ ALETINO, 1694, p. 183.

${ }^{24}$ ALETINO, 1694, p. 182.

${ }^{25}$ ALETINO, 1694, p. 185.
} 
de sua tal e não outro reputação de literato"26.

Teria sido no calor destes debates que chegou a Vico as primeiras notícias de Descartes: quase no final do isolamento em Vatolla, "que bem durou nove anos", retratado por ele como "solidão", evocando o topos do Discurso do método. Quando estava em Vatolla, lemos na Vita, "teve notícia de que a física de Renato Delle Carte havia obscurecido a fama de todas as passadas, de modo que se inflamou para conhecê-la" ${ }^{27}$. Quase como crônica, Vico reconstrói fil filo nas páginas da Vita o encanto provocado por Descartes nos intelectuais daquela cidade, que mobiliziria seu desejo de conhecê-lo: o propositor de uma nova física superior à dos antigos, juízo que De Benedictis em sua terceira Lettera Apologetica, atribuiria ao investiganti Tomaso Cornelio. A notícia o alcançava provavelmente da parte dos próprios investiganti, alguns bem próximos, como Leonardo di Capua "que habitava na mesma paróquia [...] a S. Gennaro dell'Olmo"28.

O desfecho da narrativa situa Vico entre os censores de tal encanto, vivenciado por ele melhor como estranhamento, quando conta ter sido "recebido em Nápoles como um forasteiro em sua pátria". Nas linhas seguintes da Vita ecoam sobre vários aspectos as polêmicas Lettere de De Benedictis (especialmente a terceira) ajudando a traçar o quadro de suas reações contra o cartesianismo e a tradição dos investiganti, da qual Vico certamente não foi mero expectador - é o que seu interesse juvenil por Lucrécio nos leva a crer.

Parafraseando o jesuíta, para quem Descartes "outra coisa não era que um mero apêndice de Epicuro"29, Vico colocaria em parêntesis sua suposta novidade e demonstraria os laços entre o atomismo de Epicuro e a nova física cartesiana. Vico afirma na Vita que, igual a Epicuro, Descartes reconhece "o corpo já formado" como fundamento da natureza, embora compreendam de diferentes modos os começos e a formação do universo corpuscular - para Epicuro, da "declinação casual dos atomos [...] a partir do seu próprio peso e gravidade", enquanto Descartes faz tudo começar do "ímpeto impresso a um pedaço de matéria inerte" que o constringe "a mover necessariamente segundo o movimento reto" ${ }^{30}$. Deste modo, emendou Vico,

\footnotetext{
${ }^{26}$ VICO, 2012, p. 37.

${ }^{27}$ VICO, 2012, p. 47.

${ }^{28}$ SCERBO, 1933, p. 43.

${ }^{29}$ ALETINO, 1694, p. 123.

${ }^{30}$ VICO, 2012, p. 48.
} 
Epicuro deduz o mundo natural do acaso e Descartes o assujeita ao $\mathrm{fado}^{31}$. Como esperamos demonstrar a seguir, esta não será para Vico diferença teórica de pouca monta, possibilitando repensar a direta identificação de Descartes com Epicuro. De qualquer modo, tanto num caso como no outro, o resultado era a inconveniente submissão da natureza ao dinamismo dos átomos e, por isso, seja para Epicuro seja para Descartes, "todas as infinitas várias formas dos corpos são modificações da substância corpórea" ${ }^{32}$; inconveniente, pois eximia a matéria da atuação de qualquer outro princípio: a Providência divina e o lívre-arbítrio humano, revelando-se perversa não só para a metafísica, "reputada digna de estar fechada nos chiostros" ${ }^{\text {"33 }}$, mas também para a moral.

A diferença indicada por Vico em sua Vita entre o atomismo de Epicuro e o de Descartes, embora insuficiente para salvar este último das críticas jesuíticas, ao menos tendia a atenuá-las ao descobrir no filósofo francês um caminho não percorrido pela antiga filosofia materialista. Se recuperamos nas obras de Vico as referências ao acaso do epicurismo, especialmente na Scienza nuova, onde é acusado pela negação da Providência divina, encontraremos como seu complemento necessário, culpado das mesmas consequências indesejáveis, o fado do estoicismo. Para Vico, o fato é que de diferentes modos, com o acaso ou com o fado, epicuristas e estóicos "negaram a providência divina" ${ }^{34}$. Na Scienza nuova, o fado não aparece jamais como decorrência, também, da física cartesiana, como Vico faz textualmente na Vita. Esta interessante coincidência, velada por uma omissão posterior, transporta Descartes da imediata identificação com o materialismo de Epicuro, que permanecerá operante nos termos acima expostos, para uma conformação sua às premissas do estoicismo. Para compreender que premissas são estas é instrutivo retomar a acusação do estoicismo na Scienza nuova em seu aspecto controverso: ao epicurismo parece ser justo atribuir a negação da Providência divina, pois, por princípio, acredita que os seres derivam do acaso, mas no caso do estoicismo, diferentemente, "a providência divina torna-se um elemento essencial da visão de mundo,

\footnotetext{
${ }^{31}$ VICO, 2012, p. 48.

32 VICO, 2012, p. 49.

${ }^{33}$ VICO, 2012, p. 50.

${ }^{34}$ VICO, 1992, § 5.
} 
intervindo na cosmogonia e na física, bem como na ética" ${ }^{35}$. Os estóicos argumentou Afrodisias no Tratado da Providência:

pensaram de fato que nada daquilo que existe escapa à providencia ao longo de sua existência e que tudo está repleto de Deus. Se Deus penetra realmente todos os seres é porque todas as coisas existentes retiram a formação do seu ser da vontade dos deuses, pelo fato de serem os mantenedores e os administradores de cada uma delas ${ }^{36}$.

Eles não recusariam portanto a providência divina, embora fosse correto talvez afirmá-lo no caso dos epicuristas. Claro que o problema suscitado é falso para o autor da Scienza nuova: a questão para Vico era singularizar a atuação da Providência divina no mundo das nações ou no universo histórico da humanitas, e que nada tinha a ver com a concepção que os estóicos faziam dela, de modo que, ainda assim, negariam a Providência. Nossos argumentos propõem, na verdade, uma consideração marginal ao texto da Scienza nuova apta contudo a completar detalhes da imagem de Descartes construída na Vita e delinear contornos que revelam uma fisionomia diversa do atomista dos investiganti e do epicurista de De Benedictis. Ora, os acontecimentos se comportam numa ordem necessária porque para os estóicos atua no plano material uma ferrea legislação divina, levando-nos ao encontro de Descartes naquilo que ele difere de Epicuro, ou seja, fazer o movimento começar de um ímpeto impresso nos corpos, o que não se dá senão a partir de um agente, Deus, e da sua vontade e inteligência. Embora mantendo um tom crítico e de censura, a narrativa autobiográfica de Vico seguia a nova estrada, já percorrida por outros pensadores daquela cidade, da revitalização em chave metafísica do cartesianismo, compreendendo o mundo mecanicista de Descartes submetido à necessidade porque permeado a todo instante da vontade divina.

O corpo extenso, que dá enredo ao universo da nova física, pressupõe, enquanto tal, a existência de outra realidade, não-física, incorpórea e inextensa: a ideia de extensão da geometria. Etiénne Gilson notaria uma espécie de contradição na crítica cartesiana às formas substânciais, oferecendo-nos

\footnotetext{
${ }^{35}$ THILLET, 2003, p. 31.

${ }^{36}$ AFRODISIA, 2003, p. 87.
} 
argumentos para explicar os paradoxos do cartesianismo napolitano. "Descartes jamais argumentou contra esta doutrina tal e qual" ${ }^{37}$, dirá Gilson, pois ele jamais prescindiria filosoficamente das formas escolásticas ou de substitutos equivalentes. O conceito havia sido abolido do vocabulário da ciência, embora sua semântica permanecesse indispensável e continuasse a operar em construções análogas. Para o medievalista, Descartes não eliminou a forma escolástica, simplesmente a restringiu às propriedades ideais da extensão (a largura, a profundidade, o comprimemento), isto é, transformou-a em "qualidade matemática" dando a ela o estatuto de ideia da razão - destituída de existência corpórea embora conferindo-lhe susbtância. Em vez de definição separável dos corpos, Descartes irá nomeá-la ideia, substance imatérielle ou separada da matéria ${ }^{38}$. A garantia que ele nos dá de que símbolos como extensão, movimento e número, com os quais representamos a realidade física, não são módulos convencionais e correspodem de modo suficente à substância dos objetos exteriores e independentes de nossa vontade, é de ordem metafísica: a prova da existência de um Deus infinito que é causa do meu ser e das ideias das outras substâncias criadas e do próprio Deus presentes nele: "a garantia subjetiva e relativa do Eu pensante cedeu lugar à garantia absoluta de Deus" ${ }^{39}$. Para que correspondam não só às exigências da intelecção, mas àquelas ontológicas relativas às substâncias, sem o quê as ideias não podem ser verdadeiras, Descartes não prescindiria da cognição de Deus.

\section{III}

Imiscuído com elementos do platonismo renascentista, Descartes reaparece na cena napolitana como o autor capaz de redimir a filosofia meridional do materialismo investiganti. Não só o físico atomista, Descartes teria esboçado ainda:

algumas primeiras linhas de metafísica à maneira de Platão - onde se empenha a estabelecer dois gêneros de substâncias, uma extensa

\footnotetext{
${ }^{37}$ GILSON, 1930, p. 144.

${ }^{38}$ De fato, também para o aristótelismo a forma substâncial devia ser pensada à parte, como conceito, apesar de não subsistir jamais sem os corpos, devendo ser deles abstraída, em suma, é separável dos corpos (e não separada), o que confirmaria sua inseparabilidade.

${ }^{39}$ LEOPOLDO E SILVA, 2005, p. 61.
} 
e a outra inteligênte, para demonstrar um agente sobre a matéria que de matéria não seja, tal qual é o "deus" de Platão - para ter um dia o reino também entre os chiostros, dentro dos quais, desde o século onze, havia sido introduzida a metafísica de Aristóteles ${ }^{40}$.

E desfazendo o estranhamento inicial gerado no Vico solitário em Vatolla, "ele logo se alegrou, porque [...] haviam começado a cultivar as Meditações metafísicas do próprio [Descartes]" 4 . O novo estado de ânimo de Vico provocado pelas novas leituras de Descartes, certamente diminuindo-lhe a sensação de ser estrangeiro em sua terra, coincidia com o seu debut na fior fiori dos literatos napolitanos da época: convidado a tomar parte na Accademia di Palazzo del duca di Medinaceli (1698 - 1701).

Criada pelo Vice-Rei e sediada no Palácio Real, a Academia do duque representava a inclusão e participação da classe intelectual da cidade no governo do vice-reino e, ideologicamente, o abandono do Descartes físico dos investiganti a favor de uma inspiração dualista em condição de ressaltar a autoridade do espírito na direção da corrupta corporeidade, em termos práticos, legitimando a autoridade dos intelectuais na condução da multidão refém do corpo e das paixões ${ }^{42}$. Posto de lado, as não menos importantes articulações da academia palaciana com a vida política do vice-reino, interessa-nos notar como, a partir dali, se instaurava uma nova imagem do plurifacetado Descartes, que tendia a superar as idiossincrasias do cartesianismo investiganti em seus embates com a Cúria.

De autores como Gregório Caloprese, celebrado em Nápoles pelo seu cartesianismo - referido na autobiografia de Vico "grande filósofo renatista" e, na do seu aluno Francesco Maria Spinelli, "cultíssimo em todas as ciências e sobretudo grande Filósofo Cartesiano" ${ }^{44}$-, emerge a figura do Descartes não contrário à teologia católica e ao estabelecimento de fortes laços entre o físico e o metafísico, ainda que em termos não mais escolásticos. É do aluno Spinelli um dos testemunhos mais diretos destas convicções calopresianas, incorporadas em seu método de ensino.

\footnotetext{
${ }^{40}$ VICO, 2012, p. 48.

${ }^{41}$ VICO, 2012, p. 48.

${ }^{42}$ CANTILLO, 1996, p. 19.

${ }^{43}$ VICO, 2012, p. 48.

${ }^{44}$ SPINELLI, 2007, p. 52.
} 
Segundo narra Spinelli em sua Vita, a primeira presença de Descartes nas lições do mestre Caloprese estava na explicação da Dioptrice, feita ao lado do ensino da álgebra e da explicação dos livros de Euclides, porém, como a narrativa nos faz crer, não seria esta a grande lição cartesiana de Caloprese. Para ele, Descartes era sim o descobridor de um novo método de estudo da "Teologia Natural" ou "metafísica", mais fácil e melhor que aquele escolástico. O método escolástico, explica Spinelli, gasta demasiado tempo com a definição dos Universais até oferecer a abstrata definição de Deus como o Ente; em seguida, percorre uma série quase infinita de disputas, questões e objeções em torno das propriedades deste Ente, fastidioso empenho "obrigando o estudante a empregar dois anos em aprendê-las", mas que em sua maior parte quase nada permite concluir de verdadeiro sobre este Ente, servindo mais para nos fazer perder de vista as substâncias espirituais e consumindo inutilmente o longo tempo dedicado a estes estudos; "daquele tempo apenas quinze dias não são perdidos" 45 . Na escola de Caloprese era posta em prática a lição das Meditações de Renato e deixada de lado a ratio escolástica: a fixação da mente na indagação da sua própria natureza e propriedades, o conhece-te a ti mesmo socrático que, no encadear lógico das suas descobertas, nos conduz ao conhecimento da "essência de Deus" e, por seu turno, à teologia natural.

A remissão ao conhece-te a ti mesmo socrático, interpretado em chave cartesiana, se tornaria frequente no grupo de filósofos ao redor de Caloprese: está no coração da Lição lida por Caloprese no palácio de Medinaceli Dell'origine dell'imperi e é o leitmotiv da primeira Oração Inaugural proferida por Vico na Universidade de Nápoles; e é Vico quem nos esclarece a nova fisonomia do famoso lema clássico. Em vez de evocá-lo com o escopo de "esmagar o orgulho dos homens e curvar a humana soberba", sua oração focalizaria "o divino valor daquele dito", como havia feito o "mais eloquente dos homens sábios, Cícero" 46 e também "a filosofia que nos demonstra com provas a natureza divina dos nossos ânimos" "47, inequivocamente aquela cartesiana. O renovado ensinamento calopresiano da metafísica operava "como uma viajem e uma descoberta na dimensão da interioridade", cuja vastidão

\footnotetext{
${ }^{45}$ SPINELLI, 2007, p. 66.

${ }^{46}$ VICO, 1982, p. $79(\S 4)$.

${ }^{47}$ VICO, 1982, p. 85 (§ 9).
} 
dos mundos ali encontrados revelaria já "uma compreensão do significado da metafísica cartesiana como Philosophia prima, ciência do fundamento"48. Os cânones da educação escolástica por princípio se opunham à via aberta pelas Meditações: oprimia o entendimento ao sobrecarregar a memória com confusas disputas, transformando-o "chicaneiro e não descobridor, nem verdadeiro inventor" 49 , desviando-o portanto do seu real potencial de conhecer, com clareza e brevidade, todas as coisa que a metafísica escolástica com fastídio mencionava. Descartes, libertando o entendimento da opressão:

faz [a mente] encaminhar a partir de si mesma à descoberta [...] primeiramente da sua existência independente dos corpos; depois da natureza dos Universais, dentre os quais do Ente, etc. como formados pela nossa mente [...] e o entendimento não mais agrilhoado poderá, partindo de si mesmo, andar adiante indagando mais propriedades das mentes, principalmente da sua própria, onde deve encontrar o conhecimento de todas as coisas e, com isso, fazer sempre novas descobertas não somente metafísicas, mas físicas e matemáticas, enfim, em todas as artes e ciências ${ }^{50}$.

Caloprese estabeleceria a precedência da mente inclusive em matéria de teologia. Ajudando a tecer os contornos desta posição comumente definida pelos genéricos mentalismo e espiritualismo, Spinelli nos faz ver em Caloprese a centralidade da mente na consideração seja dos objetos corpóreos seja daqueles puros ou matemáticos, também daqueles propriamente teológicos e do domínio da fé: a imaterialidade e eternidade da alma e o Ente, Deus.

Na primeira Oração Inaugural de Vico, cujo contexto argumentativo era também o de uma reflexão pedagógica sobre os estudos, o lema socrático do conhecimento de si redundava também numa teologia natural. Proferida em 1699, na abertura do ano letivo da Universidade de Nápoles, portanto, em plena a atividade da acadêmia palaciana, Vico esperava persuadir os jovens alunos, recém ingressados na Universidade, de que o exame das faculdades presentes em cada um deles logicamente conduziria ao mais importante dos

${ }^{48}$ LOJACONO, 1997, p. $71-73$

${ }^{49}$ SPINELLI, 2007, p. 66.

${ }^{50}$ SPINELLI, 2007, p. 67. 
conhecimentos, incitando o bom aproveitamento nos estudos: o da divindade do nosso ânimo. Em diálogo com os jovens que o escutam Vico lança uma interrogação cheia de implicações; pergunta: "o que significa o fato de que, logo que o ânimo alcança aquela idade em que pode servir-se da razão, de que é partícipe, subtamente desperta nele a fé em Deus Onipotente?" ${ }^{51}$. Como fragmento da peça oratória, a interrogação trazia embutida, em grandes linhas, a resposta do orador. Na contramão dos argumentos de D'Andrea, não haveria, para ele, descontinuidades entre razão e fé, ao contrário, a fé em Deus seria um despertar da racionalidade amadurecida, isto porque nossa razão é participação no intelecto divino. O que chama a atenção na oração de Vico é o recurso sutil, pois não declarado explicitamente, à autoridade de Descartes. Com a intenção de responder àquela interrogação, Vico convida seu auditório a ouvir com atenção a filosofia que prova e demonstra a divindade do nosso ânimo, e dá então notícias da metafísica de Descartes parafraseando os argumentos das Meditações. Mais que um mestre de retórica, propriamente um professor de metafísica que expõe aos alunos as ideias contindas em um tratado da disciplina, Vico expõe ao auditório um resumo das Meditações: como da dúvida Renato chega ao cogito, e da ideia inata de uma res infinita, per caussas, à existência de Deus, suma perfeição digna de ser amada e louvada ${ }^{52}$. Vico tomava partido ali da revitalização

${ }^{51}$ VICO, 1982, p. $85(\S 8)$.

${ }^{52}$ Eis na íntegra o trecho da oração de Vico: "Ainda que a mente humana seja incerta e duvide de todas as coisas, absolutamente não pode duvidar disto: do seu pensamento. Logo, já que não pode não reconhecer a consciência de ser pensamento, desta consciência do pensar deduz em primeiro lugar ser uma res; de fato, se não fosse uma res, como poderia pensar? Em seguida percebe possuir em si, inato, o conhecimento de uma res infinita; então raciocína deste modo: é necessário que haja na causa tanta grandeza quanto há no efeito que deriva daquela causa; disto deduz ainda que aquele conhecimento de uma res infinita deriva de uma res que é infinita. A este ponto o homem se reconhece limitado e imperfeito; inferindo portanto que aquele conhecimento é derivado por ele de uma res infinita, de que é apenas uma parte. Demonstrado isso raciocina assim: isto que é infinito tem em si todas as qualidades e não é privado de nenhuma delas. Disto deduz ainda que aquele conhecimento inato lhe foi dado por um ser que é o mais perfeito de todos. Depois, de novo, raciocína desta modo: o ser perfeitíssimo tem em si todas as perfeições. E ainda, mais uma vez, deduz daí: portanto nenhuma perfeição falta a ele. A isto acrescenta: a perfeição comporta que isto que é perfeito exista. E conclui enfim: logo Deus existe, e porque Deus é tudo, é digno de todo o amor. O maravilhosa potência da mente humana, que observando a si mesma nos conduz pelas mãos ao conhecimento do Sumo Bem, de 
mentalística do cartesianismo proposta pelos acadêmicos de Medinaceli e colocava-se diante do seu auditório quase como um seu propagandista.

Lojacono notou na origem deste cartesianismo, primeiro, o acesso e a leitura de um corpus amplíssimo de obras de Descartes, mas ainda as novas solicitações de um clima cultural e social transformado. Convidados a discursar no Palácio real e na presença do vice-rei, homens de Letras como Caloprese, Paolo Mattia Doria e Vico se sentiriam estímulados a refletir e discursar sobre o papel cívico dos intelectuais. Neste propício contexto, o elogio da subjetividade humana cumpria a tarefa de potencializar a condição humana na esteira da racionalidade.

Sobretudo, para Caloprese e para Doria cabia ressaltar a superioridade da mente humana em relação ao corpo e suas perversas paixões e a importância de torná-la a principal guia do nosso agir. Este dualismo de sabor cartesiano levava a termo a investigação das raízes antropológicas da vida civil, vida que as feras desconhecem totalmente, isso porque não possuem o atributo humano que chamamos alma: "aquela que somente pode discernir os bens e os males" 53 . Como poderia sobreviver a sociedade sem este discernimento? Deus nos privilegiou permitindo flertar com sua sublime natureza. Como explica Caloprese, a bondade considerada em si mesma outra coisa não é senão a perfeição das coisas, só existente, de fato, em Deus, Sumo Bem "que contém todas as perfeições" 54 . Por isso, as coisas boas, que discernimos com a ajuda da divina alma racional, devem ser desejadas e buscadas, pois possuídas, emenda Caloprese, mantêm e fazem crescer a perfeição do nosso $\mathrm{ser}^{55}$. A perfeição de Deus se confunde, neste caso, com "a imagem filosófica de um bem eterno, destinado porém a realizar-se só entre os homens na sua organização civil, e entre as coisas, nas suas relações geométricas e racionais" ${ }^{" 56}$. O bem (ou perfeição divina) presente na razão só encontra porém efetividade fora da mente, concretizado nas institiuições do viver em comum dos homens. Não é na natureza e sim na sociedade civil que a substância imaterial e metafísica encontra realização. O obstáculo para que isto ocorra sempre somos nós mesmos: o corpo e seu poder de inclinar a mente e guiar

Deus Onipotente" (VICO, 1982, p. 85-87, § 10).

${ }^{53}$ CALOPRESE, 2004, p. 558.

${ }^{54}$ CALOPRESE, 2004, p. 556.

${ }^{55}$ CALOPRESE, 2004, p. 556.

${ }^{56}$ SUPPA, 1971, p. 107. 
nossa vontade, "corpo que por si mesmo não tem nem sentido nem conhecimento". Daí o alerta de Caloprese: "não pode existir maior imperfeição em um homem quanto ter uma vontade serva do apetite e desobediente à razão" 57 . É interessante ver como o problema posto pelo corpo não encontrará solução alhures, mas se resolve no autoconhecimento: "tudo quanto existe de bom ou de mal nas operações dos homens, tudo nasce da boa ou má ideia que têm de si mesmos" $" 58$. Tudo depende, portanto, do conhece-te a ti mesmo, do autoexame que naturalmente nos faz ver que "nossa alma, como susbtância intelectual, tem uma idéia inata de Deus" $" 59$ e que o verdadeiro motor da nossa vontade não é o corpo imperfeito e corruptível da criatura e sim a eterna perfeição de Deus.

Era o que pensava também Mattia Doria. Numa carta de tom autobiográfico, intitulada L'Arte di conoscer se stesso, Doria manifestou descontentamento com a educação recebida de sua mãe, que havia incutido nele desde a infância a ideia de que Deus está no céu e que a morte é algo a se temer. Isto lhe permitiu, porém, entender que a boa educação não se dá sem a metafísica, isto é, sem que nos entendamos, de partida, possuidores das "ideias inatas da verdade, e do bom", dotados "por Deus de uma mente infinita" e, por conseguinte, a morte como acidente do corpo atuando à margem da eternidade da nossa verdadeira substância. De novo é o autoconhecimento o primeiro e mais fundamental, capaz de determinar o teor da operosidade do homem, "sujeito a sofrer infinitas tormentosas paixões quando não faz uso das ideias inatas e da inteligência que Deus lhe deu"60. O corpo e as paixões podem até desviá-lo da eleição das coisas boas e verdadeiras, isto somente se deixar de colher, nele mesmo, a perfeição e imaterialidade do seu ser - mensagem que o professor Vico ansiava ver transformada em atuação política, não a sua própria, mas dos jovens universitários presentes na sua oração.

Discursando dentro dos portões da Universidade Real de Nápoles, uma das primeiras laicas da Europa, Vico concluía sua oração advertindo os neófitos sobre a função pública da Universidade e o compromisso implícito daqueles que nela se formam, de retribuir ao Estado pela sua formação;

\footnotetext{
${ }^{57}$ CALOPRESE, 2004, p. 556.

${ }^{58}$ CALOPRESE, 2004, p. 553.

${ }^{59}$ CALOPRESE, 2004, p. 559.

${ }^{60}$ DORIA, 1981, p. 425.
} 
Estado, que aparelhando a Universidade de mestres sapientíssimos em suas disicplinas, desfechou Vico, "os convidam a estes estudos para que depois façam parte da [sua] administração [...] cobrindo aqueles cargos de que vocês serão dignos" ${ }^{\prime \prime}$. Conclusão que claramente transportava as discussões que ganhavam vida nos salões do Palácio Real para o interior da Universidade, onde, pelas mãos da juventude napolitana, poderiam virar engajamento.

\section{Referências}

AFRODISIA, Alexandre. Traitè de la Providence. Tradução francesa, introdução e notas de Pierre Thillet. Paris: Verdier, 2003.

ALETINO, Benedetto. Lettere Apolgetiche in difesa della teologia scolastica, della filosofia peripatetica. Napoli: Giacomo Raillard, 1694.

AMABILE, L. Il Santo Officio della inquisizione in Napoli. Catanazaro: Rubbetino, 1987.

BELGIOIOSO, Giulia. La variata immagine di Descartes. Gli itinerari della metafisica tra Parigi e Napoli (1690 - 1733). Lecce: Milella, 1999.

BORELLI, Antonio. D'Andrea Atomista. In: . D'Andrea atomista. L' "Apologia" e altri inediti nella polemica filosofica della Napoli di fine Seicento. Napoli: Liguori, 1995.

CALOPRESE, Gregorio. Dell'Origine dell'Imperj. In: . Opere. Introduzione e cura di Fabrizio Lomonaco e Alfonso Mirto. Napoli: Giannini, 2004.

CANTILLO, Clementina. Filosofia, poesia e vita civile in Gregorio Messere. Un contributo alla storia del pensiero meridionale tra 600 e 700. Napoli: Morano, 1996.

D'ANDREA, Francesco. Lezione. In: BORELLI, Antonio. D'Andrea atomista. L' "Apologia" e altri inediti nella polemica filosofica della Napoli di fine Seicento. Napoli: Liguori, 1995.

DESCARTES, René. Meditações sobre a filosofia primeira. Tradução portuguesa de Gustavo de Fraga. Coimbra: Almedina, 1988.

${ }^{61}$ VICO, 1982, p. 95 (§ 14). 
DORIA, Paolo Mattia. L'Arte di conoscer se stesso. In: .Manoscritti napolitani di Paolo Mattia Doria. A cura di Pasquale De Fabrizio. Galatina: Congedo, 1981.

GARIN, Eugenio. Descartes e a Itália. In: BELGIOIOSO, Giulia et al. Descartes: il metodo e i saggi. Firenze: Treccani, 1990.

GILSON, Etiénne. Étude sur le role de la pensée médiévale dans la formation du systéme cartesién. Paris: Vrin, 1930.

LEOPOLDO E SILVA, Franklin. Descartes: a metafisica da modernidade. São Paulo: Moderna, 2005.

LOJACONO, Ettore. Letture cartesiane da Cornelio a Caloprese (1638 1694). In: AGRIMI, Mario et al. Della scienza mirabile alla scienza nuova: Napoli e Cartesio (Catalogo della mostra bibliografia e iconografica). Napoli: Biblioteca Nazionale, 1997.

. Immagini di René Descartes nella cultura napoletana dal 1664 al 1755. Lecce: Conte, 2003, p. 86.

LOMONACO, Fabrizio. Descartes y los cartesianos meridionales a proposito de las Pasiones del Alma. In: . Pasiones del alma y pasiones civiles: Nápoles y Europa en los siglos XVII y XVIII. Bogotá: Planeta, 2011.

MALEBRANCHE, Nicola. Della ricerca della verità. Traduzione italiana di Felice Lunghi. Pavia: Giacomo Capelli, 1819, Tomo III.

OSBAT, L. L'Inquisizione a Napoli. Il processo agli ateisti. $1688-1697$. Roma: Edizioni di Storia e Letteratura, 1971.

RICCI, Saverio. Momenti essenziali della diffusione di Cartesio e dei 'moderni' a Napoli. In AGRIMI, Mario et al. Della scienza mirabile alla scienza nuova: Napoli e Cartesio (Catalogo della mostra bibliografia e iconografica). Napoli: Biblioteca Nazionale, 1997, p. 251.

SPINELLI, Francesco Maria. Vita, e studj scritta da lui medesimo in una lettera. Introduzione e cura di Fabrizio Lomonaco. Genova: il melangolo, 2007.

SCERBO, G. Giambattista Vico e il cartesianismo a Napoli. Roma: Angelo Signorelli, 1933. 
SUPPA, Silvio. L'Accademia di Medinacoeli: fra tradizione investiganti e nuova sceinza civile. Napoli: Istituto Italiano per gli Studi Storici, 1971. THILLET, Pierre. Introdução. In: AFRODISIA, Alexandre. Traitè de la Providence. Tradução francesa, introdução e notas de Pierre Thillet. Paris: Verdier, 2003.

TORRINI, Maurizio. Tommaso Cornelio e la ricostruzione della scienza. Napoli: Guida, 1977, p. 79.

VICO, Giambattista. I Orazione. In: Le Orazioni Inaugurali. Traduzione italiana e cura di Visconti Galeazzo. Bolonha: Il Mulino, 1982.

. Principi di Scienza nuova. Introduzione e cura di Fausto Nicolini. Napoli: Mondadori, 1992.

. Vita scritta da se medesimo. Introduzione e cura di Fabrizio Lomonaco. Napoli: Diogene, 2012.

Data de registro: 01/07/2015

Data de aceite: $30 / 07 / 2015$ 